\title{
Does pulse oximetry accurately monitor a patient's ventilation during sedated endoscopy under oxygen supplementation?
}

\author{
Hiroshi Arakawa ${ }^{1}$, MD, PhD, Mitsuru Kaise ${ }^{2}$, MD, PhD, Kazuki Sumiyama ${ }^{3}$ MD, PhD, Shoichi Saito ${ }^{3}$, MD, PhD,
} Takeshi Suzuki ${ }^{3}$, MD, PhD, Hisao $\underline{\text { Tajiri }}^{4}, \mathrm{MD}, \mathrm{PhD}$

\begin{abstract}
INTRODUCTION Pulse oximetry $\left(\mathrm{SpO}_{2}\right)$ measures oxygen saturation but not alveolar ventilation. Its failure to detect alveolar hypoventilation during sedated endoscopy under oxygen supplementation has been reported. The aim of this study was to measure the masking effect of oxygen supplementation in $\mathrm{SpO}_{2}$ when alveolar hypoventilation develops during sedated endoscopy.

METHODS A total of 70 patients undergoing sedated diagnostic colonoscopy were randomly divided into two groups oxygen supplementation group $(n=35)$ and room air breathing group $(n=35) \cdot \mathrm{SpO}_{2}$ and end-tidal carbon dioxide $\left(\right.$ etCO $\mathrm{CO}_{2}$ were measured by non-intubated capnography during the procedure for all the patients.

RESULTS The rise of et $\mathrm{CO}_{2}$ caused by alveolar hypoventilation was comparable in the two groups after sedation. $\mathrm{SpO}_{2}$ was significantly higher in the oxygen supplementation group than in the room air breathing group $(98.6 \% \pm 1.4 \%$ vs. $93.1 \% \pm 2.9 \% ; \mathrm{p}<0.001$ ) at peak etCO $\mathrm{C}_{2}$, and oxygen supplementation caused $\mathrm{SpO}_{2}$ to be overestimated by greater than $5 \%$ when compared with room air. $\mathrm{SpO}_{2}$ at peak et $\mathrm{CO}_{2}$ was reduced from the baseline before sedation for the oxygen supplementation and room air breathing groups by $0.5 \% \pm 1.1 \%$ and $4.1 \% \pm 3.1 \%$, respectively $(p<0.001)$.

CONCLUSION $\mathrm{SpO}_{2}$ alone is not adequate for monitoring alveolar ventilation during sedated endoscopy under oxygen supplementation due to possible delays in detecting alveolar hypoventilation in patients. Even if $\mathrm{SpO}_{2}$ decreases by only $1 \%$ during the procedure and its level remains near $100 \%$, physicians should consider the onset of severe alveolar hypoventilation, which requires immediate intervention.
\end{abstract}

Keywords: capnography, endoscopy, hypoventilation, pulse oximetry, sedation

\section{INTRODUCTION}

Sedation is widely performed during endoscopy to decrease patient anxiety, discomfort and pain. Sedation using a combination of opioids and benzodiazepines, however, depresses the responsiveness of the central respiratory drive to arterial carbon dioxide tension, resulting in arterial hypoxaemia accompanied by alveolar hypoventilation. ${ }^{(1)}$ Pulse oximetry $\left(\mathrm{SpO}_{2}\right)$ monitoring and oxygen supplementation are therefore used to manage hypoxaemia during sedated endoscopy. ${ }^{(1)}$ Despite its widespread use, the measurement of $\mathrm{SpO}_{2}$ has been reported to have limited utility during oxygen supplementation. ${ }^{(1-5)}$ This is because $\mathrm{SpO}_{2}$ measures arterial oxygen saturation and not alveolar ventilation..$^{(1)}$ While breathing room air, alveolar hypoventilation causes a decrease in alveolar oxygen partial pressure $\left(\mathrm{P}_{\mathrm{A}} \mathrm{O}_{2}\right)$ and an increase in alveolar carbon dioxide partial pressure $\left(\mathrm{P}_{\mathrm{A}} \mathrm{CO}_{2}\right)$. This leads to an immediate decrease of $\mathrm{SpO}_{2}$ in response to the decrease in arterial oxygen partial pressure resulting from the decrease in $\mathrm{P}_{\mathrm{A}} \mathrm{O}_{2}$. In contrast, supplemental oxygen increases inspiratory oxygen partial pressure, and $\mathrm{P}_{\mathrm{A}} \mathrm{O}_{2}$ remains high despite the increase in $\mathrm{P}_{\mathrm{A}} \mathrm{CO}_{2}$ caused by alveolar hypoventilation. Therefore, $\mathrm{SpO}_{2}$ may be overestimated because of the supplementation of oxygen without the recovery of ventilation, even when significant alveolar hypoventilation occurs. ${ }^{(3,5)}$
Capnography is acknowledged as a superior method for the evaluation of ventilation in patients. It monitors the end-tidal carbon dioxide $\left(\mathrm{etCO}_{2}\right.$ ) levels, which is theoretically more sensitive to alveolar hypoventilation than $\mathrm{SpO}_{2}$, and is the standard for general anaesthesia managed with bronchial intubation. ${ }^{(4)}$ Capnography has also been clinically demonstrated to be an earlier indicator of respiratory distress than $\mathrm{SpO}_{2}{ }^{(6,7)}$ The present study was designed to evaluate the masking effect of oxygen supplementation in $\mathrm{SpO}_{2}$ when alveolar hypoventilation develops during sedated diagnostic colonoscopy, using a novel non-intubated capnography system.

\section{METHODS}

A total of 70 patients (mean age $56.8 \pm 11.7$ years) who underwent sedated diagnostic colonoscopy were enrolled into the study. The patients fulfilled the inclusion criteria and agreed to participate in the study. The eligibility criteria included an age of 20-75 years and American Society of Anesthesiologists (ASA) class I-II (class I: healthy; class II: single controlled disease state). Exclusion criteria were ASA class III- $\mathrm{V}$, therapeutic or emergency colonoscopy, $\mathrm{SpO}_{2}<90 \%$ when breathing room air, a history of cardiopulmonary diseases or major abdominal operations, allergy to meperidine or flunitrazepam, alcoholism, use of psychotropic drugs, and pregnant or breastfeeding women.

${ }^{1}$ Division of Gastroenterology and Hepatology, Jikei University Kashiwa Hospital, Chiba, ${ }^{2}$ Department of Gastroenterology, The Toranomon Hospital, Tokyo, ${ }^{3}$ Department of Endoscopy, ${ }^{4}$ Division of Gastroenterology and Hepatology, Department of Internal Medicine, Jikei University School of Medicine, Tokyo, Japan

Correspondence: Dr Hiroshi Arakawa, Assistant Professor, Division of Gastroenterology and Hepatology, Jikei University Kashiwa Hospital, 163-1 Kashiwashita, Kashiwa, Chiba 277-8567, Japan. endosc-arakawa@jikei.ac.jp 

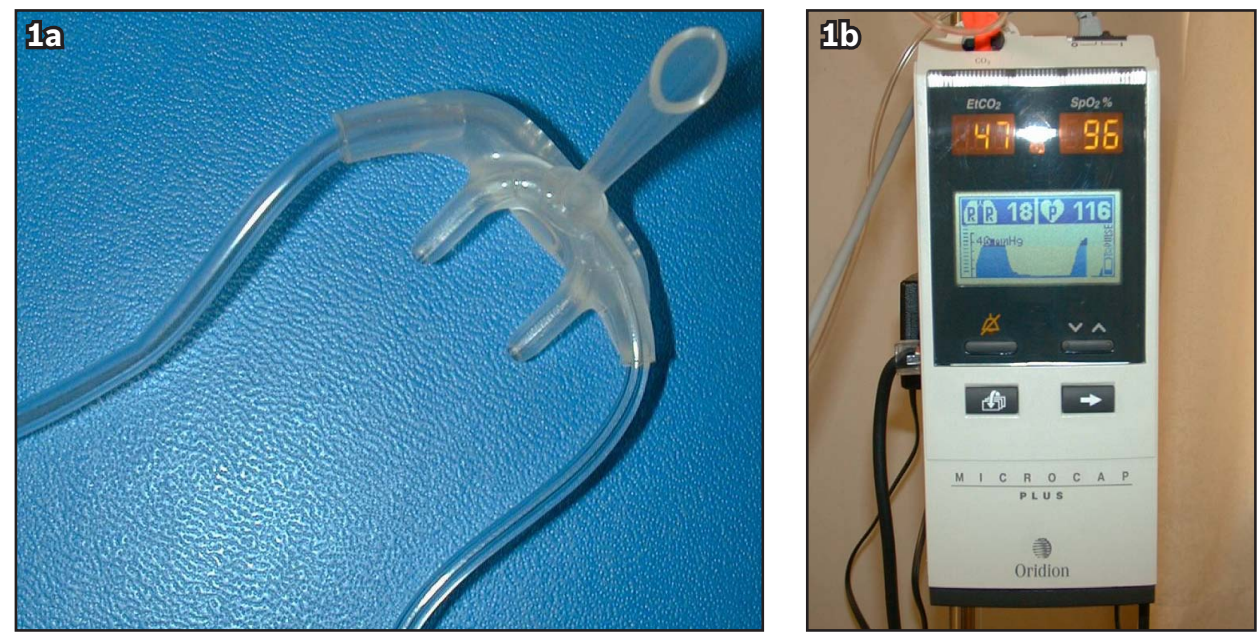

Fig. 1 Photographs show (a) a non-intubated oxygen/carbon dioxide oral-nasal cannula; and (b) a non-intubated capnography monitor with pulse oximeter (Microcap ${ }^{\circledR}$ Plus).

Patients were randomised into two study groups: (a) oxygen supplementation group (oxygen supplementation was administered routinely prior to and during the procedure at a rate of $2 \mathrm{~L} / \mathrm{min}$ ); and (b) room air breathing group (room air was breathed during the procedure; oxygen supplementation was administered if $\mathrm{SpO}_{2}$ fell below $90 \%$ for more than 20 -second intervals during the procedure).

On arrival at the endoscopy unit, the patient's medical history and records were obtained and carefully reviewed. An intravenous cannula was placed in the patient's forearm, and an automated blood pressure cuff, two-finger pulse oximeter (one for monitoring by the endoscopist and the other for capnography data sampling) and an adult-size $\mathrm{O}_{2} / \mathrm{CO}_{2}$ oral-nasal cannula were attached. The nasal cannula (Smart CapnoLine ${ }^{\mathrm{TM}}$ Plus sampling line; Oridion Medical Ltd, Needham, MA, USA) (Fig. 1a) provided oxygen at $2 \mathrm{~L} / \mathrm{min}$ and simultaneously sampled inspired and expired breath gas via the nose or mouth to measure etCO $\mathrm{C}_{2}$ in real time. The pulse oximetry probe and non-intubated $\mathrm{O}_{2} / \mathrm{CO}_{2}$ oral-nasal cannula were connected to a capnography monitor (Microcap $^{\circledR}$ Plus; Oridion Medical Ltd) (Fig.1b), which uses infrared spectroscopy to continuously and quantitatively track an absorption peak of $\mathrm{CO}_{2}$ at 4,200 nm, providing a real-time graphic display of the $\mathrm{CO}_{2}$ waveform as well as etCO $\mathrm{C}_{2}$, respiratory rate, heart rate and $\mathrm{SpO}_{2}$. Patient data were recorded every 0.10 seconds by a specialised SOTEC microcomputer (SOTEC Co, Ltd, Tokyo, Japan) linked to the Microcap ${ }^{\circledR}$ Plus capnography monitor.

The baseline $\mathrm{SpO}_{2}$ and etCO $\mathrm{CO}_{2}$ values were defined as the value measured before sedation in the room air breathing group and the value measured three minutes after the administration of $2 \mathrm{~L} / \mathrm{min}$ of oxygen in the oxygen supplementation group. Sedation and analgesia (using $0.3 \mathrm{mg}$ flunitrazepam and $35 \mathrm{mg}$ meperidine) were administered through an intravenous catheter. The depth of sedation was evaluated by an independent physician using the Observers Assessment of Alertness and Sedation scale. Additional doses of the drugs were titrated if patients exhibited signs of pain, discomfort or restlessness during the procedure.

The colonoscopic procedure was performed by six experienced staff endoscopists. Conventional $\mathrm{SpO}_{2}$, pulse rate and blood pressure were monitored by the endoscopists during the procedure, while the capnographic data were monitored by an independent physician at the bedside and were not accessible to the endoscopists. If any abnormal et $\mathrm{CO}_{2}$ or $\mathrm{CO}_{2}$ waveform changes were observed during the procedure, the position of the $\mathrm{O}_{2} / \mathrm{CO}_{2}$ oral-nasal cannula was first checked, followed by other artificial events such as a change in the head position of the patient, talking or body movements. These events were assessed by the independent physician, who recorded comments about such events in the microcomputer. When the recorded data were subsequently analysed, the artificial events were excluded from the evaluation.

Quantitative data were summarised and presented as mean \pm standard deviation. The data obtained were evaluated using the Mann-Whitney $U$ test, Wilcoxon's matched-pairs signed-rank test and chi-square test. All $p$-values were two-sided and assumed to be statistically significant at $p \leq 0.05$.

\section{RESULTS}

Of the 70 patients, 35 underwent sedated diagnostic colonoscopy with oxygen supplementation and 35 underwent the procedure while breathing room air. The demographic and clinical characteristics of patients in the two groups were similar (Table I). In both groups, the underlying disease in the ASA class II patients were hypertension and diabetes mellitus. A supplemental dose of flunitrazepam for abdominal pain or discomfort was given to three patients in the oxygen supplementation group and two patients in the room air breathing group, but no supplemental meperidine was administered to any patient in either group. One patient in the oxygen supplementation group and two patients in the room air breathing group did not complete the colonoscopy due to abdominal discomfort and pain. There were no significant cardiopulmonary or endoscopic complications that required medical intervention in either group.

There were no significant differences in the baseline values of etCO $\mathrm{O}_{2}$ between the oxygen supplementation $(37.1 \pm 2.6 \mathrm{mmHg})$ and room air breathing $(37.0 \pm 2.6 \mathrm{mmHg})$ groups. After sedation, although alveolar hypoventilation caused an increase in et $\mathrm{CO}_{2}$ 
Table I. Characteristics of participants $(n=70)$.

\begin{tabular}{|c|c|c|c|}
\hline \multirow[t]{2}{*}{ Characteristic } & \multicolumn{2}{|c|}{ Mean \pm SD } & \multirow[t]{2}{*}{ p-value } \\
\hline & $\begin{array}{c}\text { Oxygen } \\
\text { supplementation } \\
\text { group }(n=35)\end{array}$ & $\begin{array}{c}\text { Room air } \\
\text { breathing } \\
\text { group }(n=35)\end{array}$ & \\
\hline Age (yrs) & $54.4 \pm 10.8$ & $59.2 \pm 12.1$ & NS \\
\hline Male-to-female ratio & $24: 11$ & $22: 13$ & NS \\
\hline BMI $\left(\mathrm{kg} / \mathrm{m}^{2}\right)$ & $24.1 \pm 4.0$ & $22.7 \pm 3.2$ & NS \\
\hline \multicolumn{4}{|l|}{ ASA status (no.) } \\
\hline Class I & 23 & 24 & NS \\
\hline Class II & 12 & 11 & \\
\hline Procedure time $(\mathrm{min})$ & $19.2 \pm 7.8$ & $22.3 \pm 9.3$ & NS \\
\hline \multicolumn{4}{|l|}{ Dosage } \\
\hline Flunitrazepam (mg) & $0.3 \pm 0.1$ & $0.3 \pm 0.1$ & NS \\
\hline Meperidine (mg) & 35 & 35 & NS \\
\hline OAA/S score & $3.6 \pm 0.6$ & $3.7 \pm 0.7$ & NS \\
\hline
\end{tabular}

ASA: American Society of Anesthesiologists; BMI: body mass index; OAA/S: Observers Assessment of Alertness and Sedation; NS: not significant; SD: standard deviation

in each group, there was no significant difference in the peak etCO $\mathrm{O}_{2}$ during the procedure between patients in the two groups (oxygen supplementation: $44.9 \pm 4.1 \mathrm{mmHg}$ vs. room air breathing: $44.1 \pm 4.0 \mathrm{mmHg} ; \mathrm{p}=0.4$ ). The mean increase in etCO $\mathrm{C}_{2}$ at its peak from baseline was $7.7 \pm 3.3 \mathrm{mmHg}$ in the oxygen supplementation group and $7.0 \pm 2.6 \mathrm{mmHg}$ in the room air breathing group (Fig. 2).

$\mathrm{SpO}_{2}$ before oxygen administration in the oxygen supplementation group was $97.9 \% \pm 1.4 \%$, which was nearly comparable to the baseline $\mathrm{SpO}_{2}$ value seen among patients in the room air breathing group ( $p=0.21$; data not shown). The baseline $\mathrm{SpO}_{2}$ value was $99.2 \% \pm 1.2 \%$ in the oxygen supplementation group and $97.3 \% \pm 2.1 \%$ in the room air breathing group. After sedation, $\mathrm{SpO}_{2}$ decreased as alveolar hypoventilation developed in each group, and the $\mathrm{SpO}_{2}$ at peak etCO $\mathrm{C}_{2}$ was significantly increased by more than $5 \%$ in the oxygen supplementation group when compared with the room air breathing group $(98.6 \% \pm 1.4 \%$ vs. $93.1 \% \pm 2.9 \% ; p<0.001)$. The mean reduction in $\mathrm{SpO}_{2}$ from baseline at peak etCO $\mathrm{O}_{2}$ was significantly lower in the oxygen supplementation group than in the room air breathing group $(0.5 \% \pm 1.1 \%$ vs. $4.1 \% \pm 3.1 \%$; $\mathrm{p}<0.001$ ) (Fig. 3). There were no significant differences in the respiratory rate between the two groups at the time of baseline and peak etCO ${ }_{2}$.

\section{DISCUSSION}

Our study showed that the masking effect of oxygen supplementation resulted in an overestimation of $\mathrm{SpO}_{2}$ by greater than $5 \%$ above the values in patients breathing room air when peak alveolar hypoventilation occurred, although the decrease in $\mathrm{SpO}_{2}$ was only $0.5 \%$ below the baseline at that time. These findings demonstrate that $\mathrm{SpO}_{2}$ monitoring in oxygen supplementation provides little information about the adequacy of alveolar hypoventilation, as previously reported. ${ }^{(1,2,5)}$ As $\mathrm{SpO}_{2}$ monitoring is the standard technique used during sedated endoscopy, and capnography is usually not available

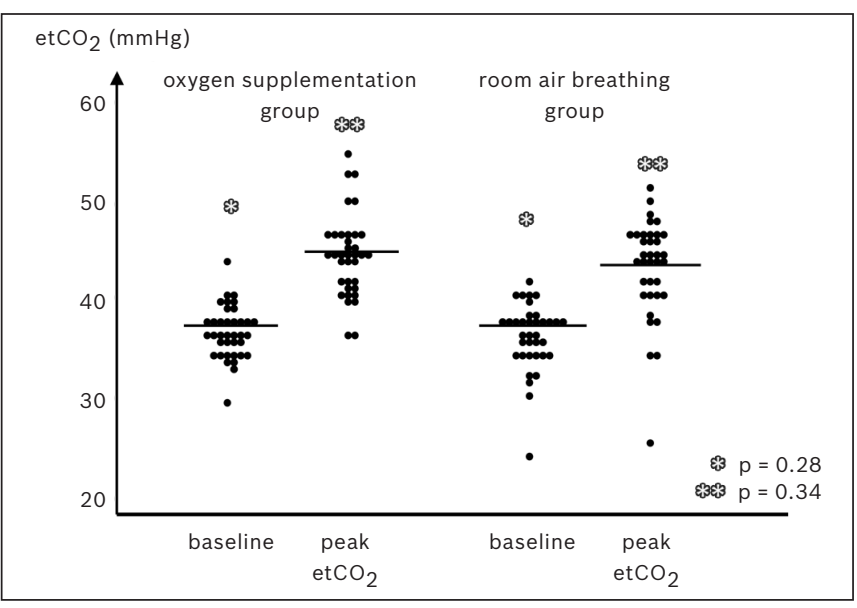

Fig. 2 Graph shows the changes of end-tidal carbon dioxide (etCO in each group.

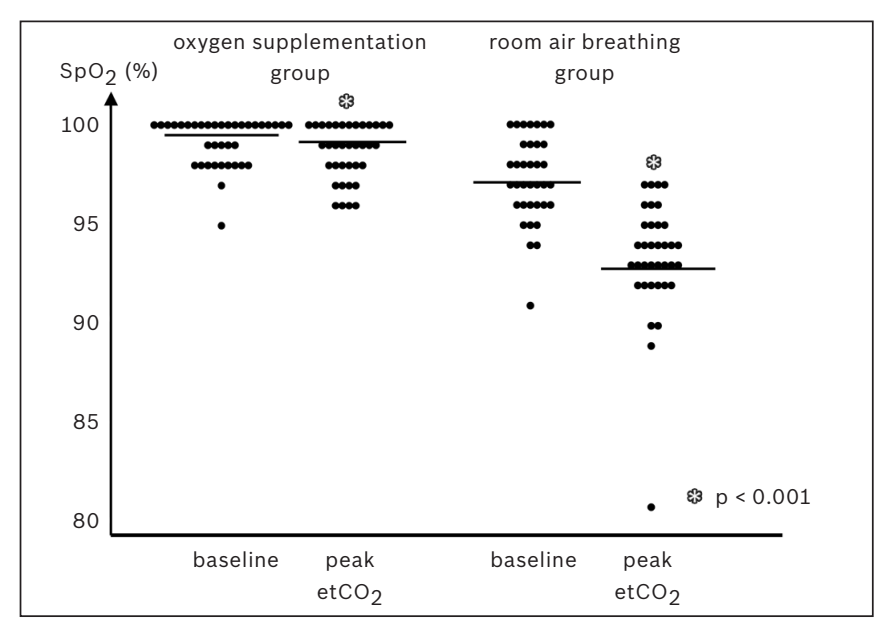

Fig. 3 Graph shows the changes of pulse oximetry $\left(\mathrm{SpO}_{2}\right)$ in each patient group.

in the gastrointestinal endoscopy unit, physicians usually predict a patient's alveolar ventilation status during a sedated endoscopy procedure solely by $\mathrm{SpO}_{2}$ monitoring. When alveolar hyperventilation occurs in a patient breathing room air, $\mathrm{SpO}_{2}$ decreases rapidly; it is a useful indicator of alveolar ventilation as well as oxygenation. ${ }^{(5)}$ However, when oxygen supplementation is given, the physician should note that alveolar hypoventilation may worsen after sedation even if a high $\mathrm{SpO}_{2}$ value is being recorded. Also, a decrease in $\mathrm{SpO}_{2}$ by just $1 \%$, even if the value remains at $98 \%$, should prompt the physician to consider the onset of severe alveolar hypoventilation or apnoea, which requires immediate intervention.

The indications for capnography during sedated endoscopy are widely contested. Sedation-related mortality in gastrointestinal endoscopy is generally very rare, with a prevalence ranging from $1 / 10,000$ to $3 / 100,000 .^{(8-10)}$ Respiratory depression during procedural sedation is defined as $\mathrm{SpO}_{2}<90 \%$, etCO $>50 \mathrm{mmHg}$ or apnoea (absence of et $\mathrm{CO}_{2}$ waveform). It is critical that respiratory depression be detected early so that intervention (such as reversal of sedation) can be implemented to prevent respiratory arrest, even if only one of these criteria is found to be applicable, regardless of the $\mathrm{SpO}_{2}$ value. ${ }^{(11)}$ Capnography is considered to be superior to $\mathrm{SpO}_{2}$ for the detection of early 
respiratory depression during procedural sedation, ${ }^{(6,7,12)}$ and it can detect alveolar hypoventilation even when oxygen supplementation is given; in this study, detection would have been impossible using $\mathrm{SpO}_{2}$ monitoring alone. Deep sedation strongly suppresses the patient's respiration and often causes upper airway obstruction and apnoea, which requires intervention and oxygen supplementation. Therefore, the authors propose that et $\mathrm{CO}_{2}$ monitoring is indispensable for endoscopy that requires deep sedation with routine oxygen supplementation. In contrast, mild-to-moderate sedation usually maintains the patency of the patient's upper airway and adequate spontaneous ventilation. Thus, the routine use of capnography monitoring does not appear to reduce sedation-related comorbidity and may not be necessary for patients under mild-to-moderate sedation. ${ }^{(13)}$ However, deep sedation frequently occurs during endoscopy despite the intent to induce moderate sedation, especially in patients undergoing endoscopic cholangiopancreatography and endoscopic ultrasonography. ${ }^{(14)}$ A recent high-volume randomised controlled study showed that capnography-based ventilation monitoring for these types of elective endoscopy procedures significantly improved patient safety by reducing the frequency of hypoxaemia, severe hypoxaemia and apnoea. ${ }^{(15)}$ Other potential predictors of respiratory compromise during sedated endoscopy are currently under investigation, and they include variables such as old age, history of cerebrovascular accidents, chronic obstructive pulmonary disease and cardiac disease, unfit physical status (ASA class III-V) and types of sedatives used. ${ }^{(3,13,16)}$ ASA guidelines state that capnography should be considered for any patient receiving deep sedation, whose ventilatory function cannot be adequately observed during a procedure in which the sedation is performed by a nonanaesthesiologist. ${ }^{(17)}$ This ASA statement is also cited in the guidelines of the American Society of Gastrointestinal Endoscopy. ${ }^{(18)}$

This study is not without its limitations. While no significant respiratory events occurred in any of our patients, the clinical impact of monitoring et $\mathrm{CO}_{2}$ could not be ascertained in this study due to the small sample size and the relatively healthy state of our patients. Further studies are necessary in order to determine the usefulness of capnography in accurately monitoring patients' ventilation during sedated endoscopy under oxygen supplementation. Nonetheless, the present study highlights the pitfall of monitoring $\mathrm{SpO}_{2}$ alone in patients undergoing sedated endoscopy with oxygen supplementation, as it could lead to a possible delay in detecting alveolar hypoventilation.

\section{REFERENCES}

1. Hutton $P$, Clutton-Brock $T$. The benefits and pitfalls of pulse oximetry. BMJ 1993; 307:457-8.

2. Davidson JAH, Hosie HE. Limitations of pulse oximetry: respiratory insufficiency - a failure of detection. BMJ 1993; 307:372-3.

3. Freeman ML, Hennessy JT, Cass OW, Pheley AM. Carbon dioxide retention and oxygen desaturation during gastrointestinal endoscopy. Gastroenterology 1993; 105:331-9.

4. Waring JP, Baron TH, Hirota WK, American Society for Gastrointestinal Endoscopy, Standards of Practile Committee, et al Guidelines for conscious sedation and monitoring during gastrointestinal endoscopy. Gastrointest Endosc 2003; 58:317-22.

5. Fu ES, Downs JB, Schweiger JW, Miguel RV, Smith RA. Supplemental oxygen impares detection of hypoventilation by pulse oximetry. Chest 2004; 126:1552-8.

6. Vargo JJ, Zuccaro G Jr, Dumot JA, et al. Automated graphic assessment of respiratory activity is superior to pulse oximetry and visual assessment for the detection of early respiratory depression during therapeutic upper endoscopy. Gastrointest Endosc 2002; 55:826-31.

7. Lightdale JR, Goldmann DA, Feldman HA, et al. Microstream capnography improves patient monitoring during moderate sedation: a randomized controlled trial. Pediatrics 2006; 117:e1170-8.

8. Thompson AM, Wright DJ, Murray W, et al. Analysis of 153 deaths after upper gastrointestinal endoscopy: room for improvement? Surg Endosc 2004; 18:22-5.

9. Freeman ML, Nelson DB, Sherman S, et al. Complication of endoscopic biliary sphincterotomy. N Engl J Med 1996; 335:909-18.

10. Yoshino J. [5th report of endoscopic complication: results of the Japan Gastroenterological Endoscopy Society survey from 2003 to 2007]. Gastroenterol Endosc 2010; 52:95-103. Japanese.

11. Miner JR, Heegaard W, Plummer D. End-tidal carbon dioxide monitoring during procedural sedation. Acad Emerg Med 2002; 9:275-80.

12. Waugh JB, Epps CA, Khodneva YA. Capnography enhances surveillance of respiratory events during procedural sedation: a meta-analysis. J Clin Anesth 2011; 23:189-96.

13. Koniaris LG, Wilson S, Drugas G, Simmons W. Capnographic monitoring of ventilatory status during moderate (conscious) sedation. Surg Endosc 2003; 17:1261-5.

14. Patel S, Vargo JJ, Khandwala F, et al. Deep sedation occurs frequently during elective endoscopy with meperidine and midazolam. Am J Gastroenterol 2005; 100:2689-95.

15. Qadeer MA, Vargo J, Dumot JA, et al. Capnographic monitoring of respiratory activity improves safety of sedation for endoscopic cholangiopancreatography and ultrasonography. Gastroenterology 2009; 136:1568-76.

16. Bell GD, McCloy RF, Charlton JE, et al. Recommendations for standards of sedation and patient monitoring during gastrointestinal endoscopy. Gut 1991; 32:823-7.

17. American Society of Anesthesiologists Task Force on Sedation and Analgesia by Non-Anesthesiologists. Practice guidelines for sedation and analgesia by non-anesthesiologist. Anesthesiology 2002; 96:1004-17

18. Standards of practice committee of the American Society for Gastrointestinal Endoscopy. Sedation and anesthesia in GI endoscopy. Gastrointest Endosc 2008; 68:815-26. 